\title{
Distribution and function of the peptide transporter PEPT2 in normal and cystic fibrosis human lung
}

\author{
D A Groneberg, P R Eynott, F Döring, Q Thai Dinh, T Oates, P J Barnes, K F Chung, \\ H Daniel, A Fischer
}

Thorax 2002;57:55-60

See end of article for authors' affiliations

Correspondence to

Professor A Fischer,

Department of Pediatric

Pneumology and

Immunology, BMFZ,

D-13353 Berlin, Germany;

axel.fischer@charite.de

Revised version received 12 July 2001

Accepted for publication

14 August 2001

\begin{abstract}
Background: Aerosol administration of peptide based drugs has an important role in the treatment of various pulmonary and systemic diseases. The characterisation of pulmonary peptide transport pathways can lead to new strategies in aerosol drug treatment.

Methods: Immunohistochemistry and ex vivo uptake studies were established to assess the distribution and activity of the $\beta$-lactam transporting high affinity proton coupled peptide transporter PEPT2 in normal and cystic fibrosis human airway tissue.

Results: PEPT2 immunoreactivity in normal human airways was localised to cells of the tracheal and bronchial epithelium and the endothelium of small vessels. In peripheral lung immunoreactivity was restricted to type II pneumocytes. In sections of cystic fibrosis lung a similar pattern of distribution was obtained with signals localised to endothelial cells, airway epithelium, and type II pneumocytes. Functional ex vivo uptake studies with fresh lung specimens led to an uptake of the fluorophore conjugated dipeptide derivative D-Ala-L-Lys-AMCA into bronchial epithelial cells and type II pneumocytes. This uptake was competitively inhibited by dipeptides and cephalosporins but not ACE inhibitors, indicating a substrate specificity as described for PEPT2.

Conclusions: These findings provide evidence for the expression and function of the peptide transporter PEPT2 in the normal and cystic fibrosis human respiratory tract and suggest that PEPT2 is likely to play a role in the transport of pulmonary peptides and peptidomimetics.
\end{abstract}

$\mathrm{B}$ acterial infections play a crucial role in the progression of chronic lung diseases such as cystic fibrosis (CF) and lead, via a progressive destruction of lung tissue, to respiratory failure. ${ }^{1}$ Infections of the lower respiratory tract invariably occur in patients with CF and, despite major advantages in antibiotic drug therapy, pneumonia remains a major cause of morbidity and mortality. ${ }^{2}$ Since the local concentration of antimicrobial agents in the lung is the most important factor for a successful eradication of bacteria, the alveolar and bronchial epithelium is a site with major significance for drug delivery and treatment. ${ }^{3}$

Direct delivery of antibiotics to the lower airways by aerosol administration has potential advantages. Deposition to the alveolar site of the infection can reach high local concentrations ${ }^{4}$ and therefore inhaled drugs can reduce the occurrence of serious systemic adverse effects by dose reduction. Given the central role of antibiotic treatment and the multitude of clinical studies concerning systemic and topical antibiotic therapy, ${ }^{5-7}$ the identification of molecular and cellular pathways for antibiotic transport in the airway epithelium is of particular interest.

A new family of $\beta$-lactam transporting proton coupled oligopeptide transporters has been cloned from mammalian epithelial cells of kidney, ${ }^{8-10}$ brain,, ${ }^{11}$ and intestine ${ }^{12-15}$ in the past years. They all share a high degree of homology and belong to the PTR family of peptide transporters. ${ }^{16}$

Whereas the mammalian isoform PEPTI has been localised to intestinal ${ }^{17-19}$ and renal epithelial cells, ${ }^{2021}$ PEPT2 is expressed in a variety of tissues including kidney, lung, brain, and mammary gland. ${ }^{20-24}$ Both peptide transporters mediate electrogenic uphill peptide and peptidomimetic transport by coupling substrate translocation to a transmembrane electrochemical proton gradient that serves as the driving force. ${ }^{25} \mathrm{In}$ addition to transporting dipeptides and tripeptides, both isoforms are of major pharmaceutical interest because they also provide a transport route for various peptidomimetic drugs. Besides $\beta$-lactam antibiotics, antiviral compounds (valacyclovir, zidovudine) and $\delta$-aminolevulinic acid ( $\delta$-ALA) have been identified as substrates of the peptide transporters. ${ }^{1622}$ Since $\beta$-lactams are used in the treatment of pulmonary infections, it is of particular interest to study the expression, function, and possible localisation of peptide transporters in the normal and functionally impaired human respiratory tract.

\section{METHODS \\ Tissues}

For immunohistochemical analysis, normal human lung tissue samples from seven patients who died without pulmonary involvement and had no history of lung disease, peripheral lung tissue samples without tumour infiltration from five patients with central bronchial carcinoma, and seven CF tissue samples were provided by the Departments of Pathology, University of Marburg and University of Giessen, and from the Royal Brompton Hospital and National Heart and Lung Institute, Imperial College of Science, Technology and Medicine, London. The tissue sections were considered as histologically normal when no inflammatory infiltrations were found and the Reid's index was less than 0.4. The Reid's index was estimated by the ratio of the thickness of the submucosal glands to the thickness of the bronchial wall.

For the uptake studies histologically normal peripheral lung tissues were obtained from the five patients with central bronchial carcinoma and from the seven patients with CF. All tissues used were obtained from surplus remnants with informed consent of the patients and protocols were approved by the institutional review board.

\section{Immunohistochemistry}

The tissues were immersion fixed with $4 \%$ phosphate buffered paraformaldehyde (PFA) overnight. The biopsy specimens 
were then washed repeatedly with $0.1 \mathrm{M}$ phosphate buffer and stored overnight in cold $\left(4^{\circ} \mathrm{C}\right) 18 \%$ sucrose containing $0.1 \mathrm{M}$ phosphate buffer. Tissues were mounted on filter paper in optimum cutting temperature compound (OCT) and frozen in liquid nitrogen. For immunohistochemical analysis the fixed biopsy specimens were cut in a cryostat into $6-8 \mu \mathrm{m}$ sections, mounted on gelatin coated glass slides, and air dried for 2 hours. After rinsing in phosphate buffered saline (PBS), non-specific labelling was blocked by coating with preincubation serum $(0.1 \mathrm{M}$ phosphate buffer containing $1 \%$ bovine serum albumin and 10\% normal swine serum) for 1 hour at room temperature. After washing in PBS the tissues were incubated with a rabbit polyclonal anti-human-PEPT2 serum $^{26}$ diluted 1:1000 in the preincubation solution at $4^{\circ} \mathrm{C}$ overnight. After overnight incubation and repeated washing steps with PBS, the sections were subsequently incubated with biotinylated goat anti-rabbit IgG (Amersham, Braunschweig, Germany; 1:200) for 1 hour at room temperature. Secondary antiserum was detected with a Streptavidin-Texas Red conjugate (Amersham; 1:50). Specificity of the antibody reaction was verified in parallel sections which were incubated either with the primary antiserum that had been preabsorbed with the corresponding antigenic peptide (concentration $20 \mu \mathrm{g}$ protein $/ \mathrm{ml}$ diluted antiserum) or only the secondary antibodies. Slides were mounted in carbonate buffered glycerol (pH 8.6) and viewed using an Olympus BX 60 microscope with epifluorescence detection. The immunoreactivity within the different cells was scored independently by two blinded observers as strongly positive $(+++)$, moderately positive $(++)$, weakly positive $(+)$, or negative $(0)$. The immunointensities within the different areas were also compared ( 10 sections per tissue).

\section{Ex vivo uptake studies}

Directly after surgical resection for lung tumours or cystic fibrosis the specimens were stored in cold Ringer's solution and reviewed for pathological examination. The tissues were transferred to Eagle's minimum essential medium (MEM21011 , Gibco, $37^{\circ} \mathrm{C}$, gased with $95 \% \mathrm{O}_{2} / 5 \% \mathrm{CO}_{2}$ ) and standardised uptake experiments were performed. The tissues were incubated with MEM-21011 containing $25 \mu \mathrm{M}$ D-Ala-L-Lys-N- epsilon-7-amino-4-methylcoumarin-3-acetic acid (D-Ala-LLys-AMCA) which has previously been shown to be a specific substrate. ${ }^{27-30}$ For competitive inhibition studies $25 \mu \mathrm{M}$ D-AlaL-Lys-AMCA plus $1 \mathrm{mM}$ of the unlabelled competitive dipeptide glycyl-L-glutamine, $1 \mathrm{mM}$ unlabelled cefadroxil or $1 \mathrm{mM}$ unlabelled captopril was used. Controls included the omission of the different labelled or unlabelled substrates, incubations performed at $4^{\circ} \mathrm{C}$, or by adding the transport inhibitor diethylpyrocarbonate. ${ }^{3132}$ The incubations were stopped after 20 minutes by repeated washing steps with ice cold unlabelled MEM. Immersion fixation was then performed using freshly prepared 4\% PFA in PBS at pH 7.4 for 2 hours. The tissues were subsequently immersed in a sucrosePBS solution adjusted to $800 \mathrm{mosmol} / \mathrm{kg}$ for cryoprotection and shock frozen in liquid nitrogen cooled isopentane. After processing to $6-8 \mu \mathrm{m}$ cryostat sections the slides were examined with epifluorescence microscopy. The cellular uptake activity was measured as positive intracellular AMCA fluorescence compared with the immunoreactivity for PEPT2 and scored independently by two blinded observers as strongly positive $(+++)$, moderately positive $(++)$, weakly positive $(+)$ or negative $(0)$ immunoreactivity for each cell type. Reporter molecule uptake into different areas were also compared ( 10 sections per tissue).

\section{RESULTS}

\section{Localisation of PEPT2 immunoreactivity}

In sections of histologically normal human lung immunohistochemical analysis for PEPT2 protein revealed staining of tracheal, bronchial, and smaller airway epithelial cells (fig 1). The endothelium of small vessels was also positive ( fig l). The immunoreactivity was of a non-granular type and was especially strong at the apical cellular membrane. There was no staining of bronchial glands. In the alveolar spaces type II pneumocytes were stained cytoplasmatically (fig lC). The immunofluorescence signal of the different positive cell types was the same in all the sections examined. To determine possible impairment of the transporter in chronic airway diseases, CF lung tissues obtained after lung transplantation were studied. The pattern of distribution showed a similar quality
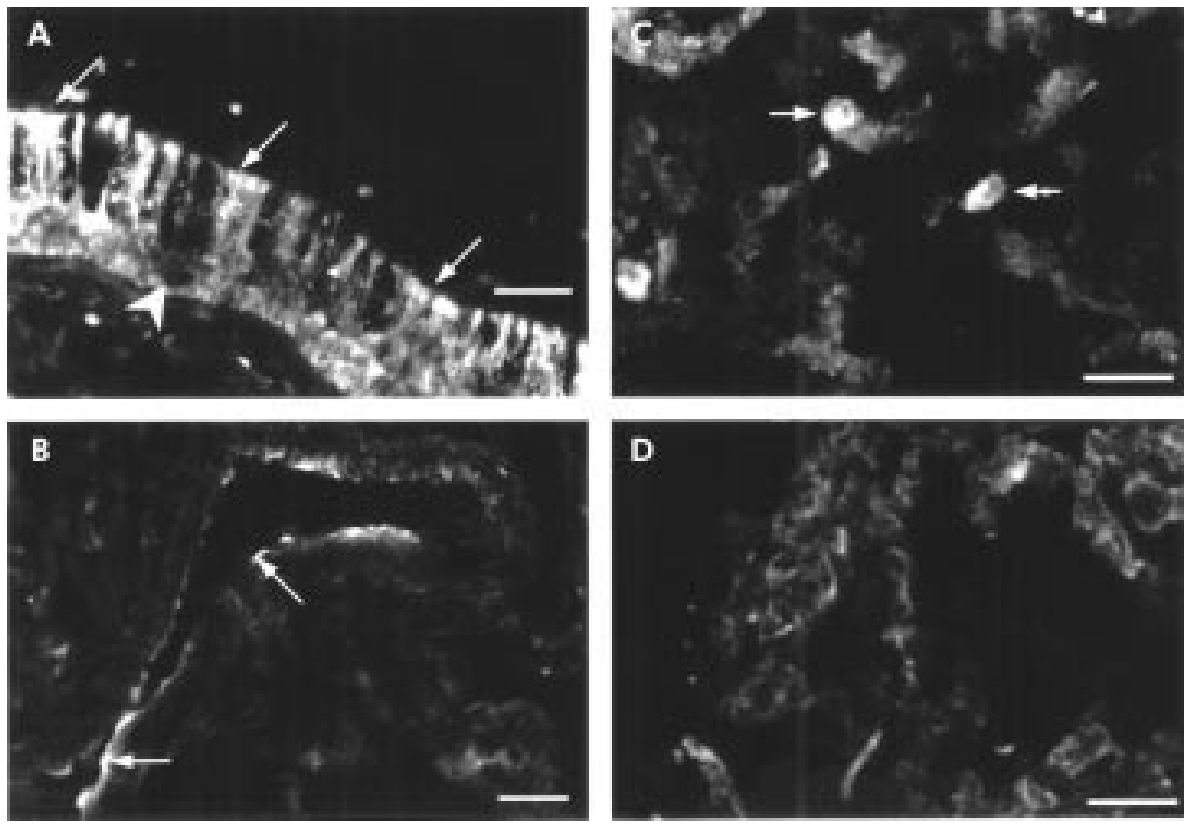

Figure 1 PEPT2 immunoreactivity in normal human lung; $8 \mu \mathrm{m}$ cryostat sections of human airways were subjected to immunohistochemical analysis. In the airways PEPT2 immunoreactivity was localised to (A) the tracheal epithelium (arrows) and (B) the endothelial cells of the submucosal venules (arrows). Goblet cells did not stain (arrowhead in A). (C) In the alveolar spaces type II pneumocytes (arrows) displayed immunoreactivity. (D) Preabsorption. Bar $=30 \mu \mathrm{m}$. 

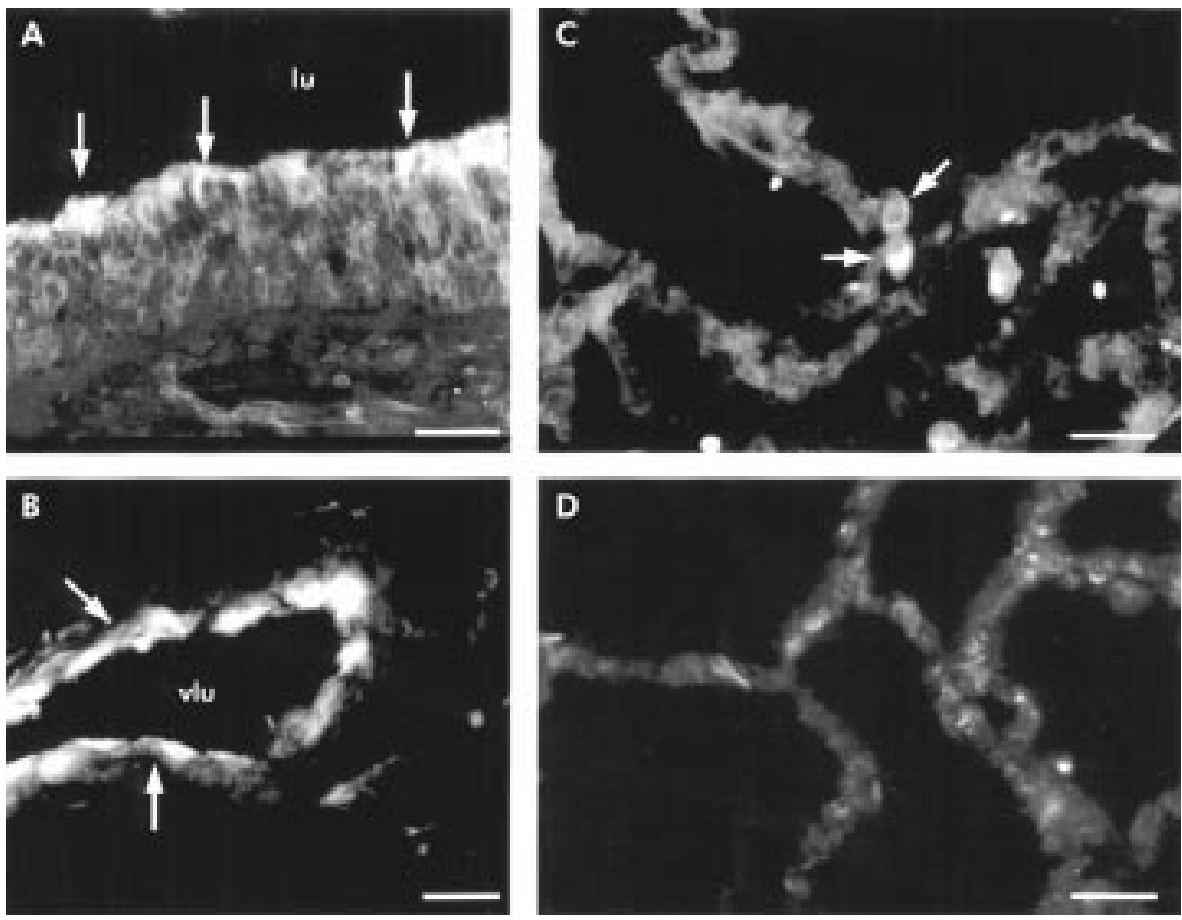

Figure 2 Cellular localisation of PEPT2 immunoreactivity in CF lungs. Immunohistochemical analysis was carried out on $8 \mu \mathrm{m}$ cryostat sections of a CF lung specimen. PEPT2 immunoreactivity was located in (A) epithelial cells of the bronchi, $(B)$ endothelial cells of the submucosal venules, and (C) type II pneumocytes. (D) Preabsorption. Bar $=30 \mu \mathrm{m}(\mathrm{A}, \mathrm{C}, \mathrm{D}), 15 \mu \mathrm{m}(\mathrm{B})$

with signals in the respiratory epithelium, endothelial cells of subepithelial veins in larger airways, and type II pneumocytes (fig 2).

Comparison between the two groups revealed that the intensity of staining within the different cell types was the same (table 1) and that there was no difference between the various areas or sections.

Immunofluorescence of the described structures was completely abolished after incubation with control serum, anti-PEPT2 serum preabsorbed with the coupled antigenic peptide (figs 1D, 2D), or when primary or secondary antibodies were omitted (data not shown).

\section{Ex vivo uptake studies}

For functional analysis of peptide transport in the peripheral lung, ex vivo uptake studies employing a fluorophore conjugated dipeptide were performed on normal (fig 3) and CF (fig 4) lung specimens. Incubation of peripheral lung sec-

\begin{tabular}{|c|c|c|}
\hline Tissue structure & Normal & Cystic fibrosis \\
\hline \multicolumn{3}{|l|}{ Epithelial cells } \\
\hline Bronchial & +++ & +++ \\
\hline Bronchiolar & +++ & +++ \\
\hline Alveolar type I & 0 & 0 \\
\hline Alveolar type II & +++ & +++ \\
\hline Macrophages & 0 & 0 \\
\hline Nerve fibres & 0 & 0 \\
\hline \multicolumn{3}{|c|}{ Submucosal endothelium } \\
\hline Arteries & ++ & ++ \\
\hline Veins & ++ & ++ \\
\hline Capillaries & 0 & 0 \\
\hline \multicolumn{3}{|l|}{ Smooth muscle } \\
\hline Airway & 0 & 0 \\
\hline Vascular & 0 & 0 \\
\hline Chondrocytes & 0 & 0 \\
\hline
\end{tabular}

tions from patients who had undergone surgery for central bronchial carcinoma with $25 \mu \mathrm{M}$ D-Ala-L-Lys-AMCA in Eagle's MEM solution led to an uptake of the reporter molecule followed by intracellular accumulation of AMCA fluorescence in type II pneumocytes (fig $3 \mathrm{~B}$ ) and epithelial cells of the small bronchi and bronchioles (fig 3A). The signal was localised to the cytoplasm without any specific subcellular pattern and was equally strong within the different cell types (table 2). No difference in fluorescence intensity was seen within the different areas.

In tissues of CF lungs there was a similar uptake pattern into epithelial cells of small airways (fig 4A) and type II pneumocytes (figs 4B, C). Although the cellular distribution pattern was identical to that in specimens of normal lung (table 2), large areas of the CF tissues were obstructed by mucus and the reporter molecule did not penetrate well into these areas, resulting in weak staining. While $100 \%$ of the examined section areas revealed uptake into all PEPT2 expressing cells, only $77 \%$ of the CF areas were penetrated and revealed full uptake of the reporter molecule.

For inhibition studies incubation with solutions containing D-Ala-L-Lys-AMCA and higher concentrations (1 mM) of unlabelled glycyl-L-glutamine, cefadroxil, or captopril were performed. The presence of either glycyl-L-glutamine in normal (fig 3C) and CF tissues (fig 4D) and cefadroxil in normal (fig 3E) and CF lungs (fig 4F) resulted in a complete reduction in the accumulation of fluorescence in normal tissues. However, the accumulation of D-Ala-L-Lys-AMCA by bronchial epithelium and type II cells was not reduced by captopril-that is, it was transported by PEPTl but not by PEPT2 (data not shown). Control experiments using the addition of the His residue specific inhibitor diethylpyrocarbonate or omission of the labelled dipeptide did not show any accumulation of the labelled dipeptide (figs 3D and 4E). Incubations performed at $4^{\circ} \mathrm{C}$ also did not result in accumulation of fluorescence (figs $3 \mathrm{~F}$ and $4 \mathrm{G}$ ), indicating that passive processes are not involved in the uptake of the reporter molecule. 

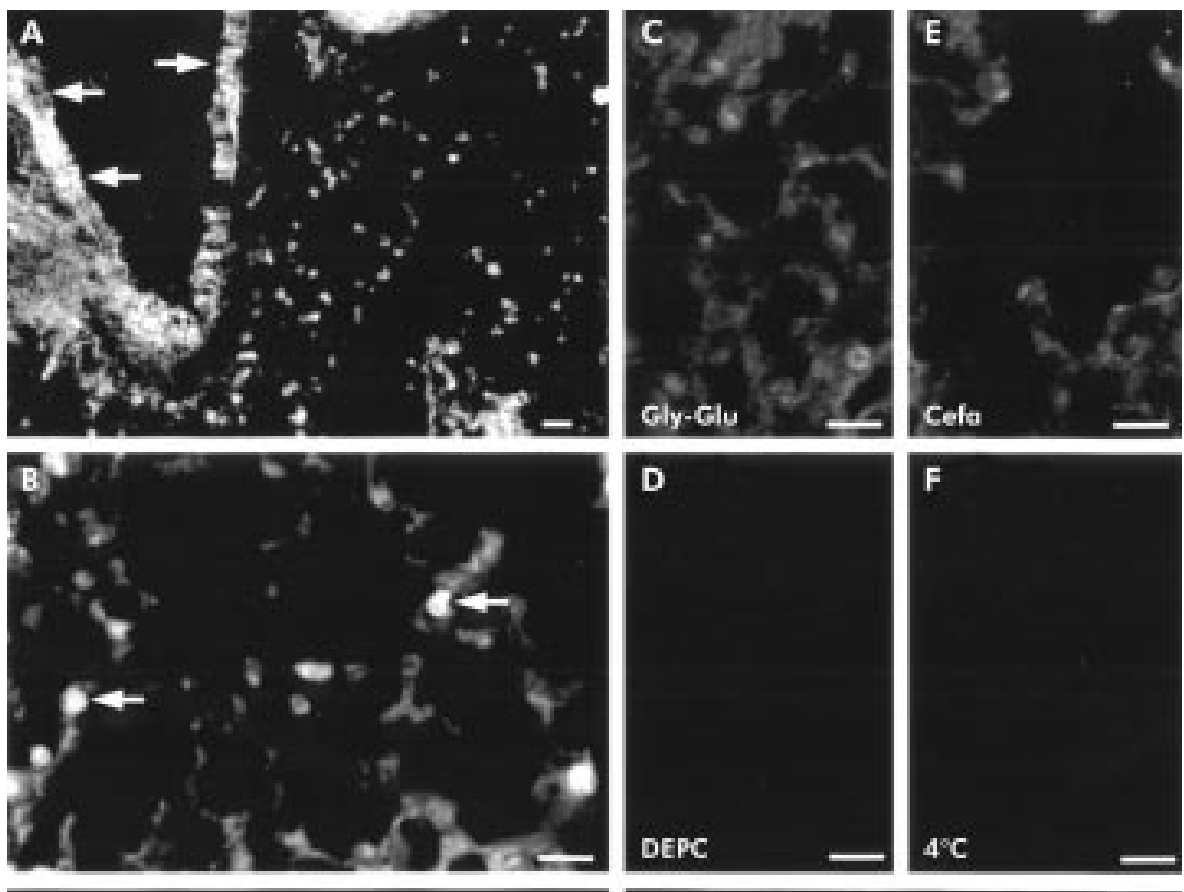

Uploke

Inthibitien

Figure 3 Ex vivo uptake studies in a normal lung specimen. Incubation of normal peripheral lung tissues with $25 \mu M$ D-Ala--Lys-AMCA resulted in dipeptide uptake and intracellular fluorescence that was restricted to (A) bronchial cells and (B) type II pneumocytes. No signal in type II cells was seen as a result of adding $1 \mathrm{mM}$ of (C) competitive glycyl---glutamine or (E) cefadroxil to the same concentration of

D-Ala--Lys-AMCA. Incubations at $4^{\circ} \mathrm{C}$ (F) and in the presence of DEPC (D) also did not exhibit transport activity and fluorescence accumulation. Bar $=22 \mu \mathrm{m}(\mathrm{A}), 42 \mu \mathrm{m}(\mathrm{B}-\mathrm{F})$.
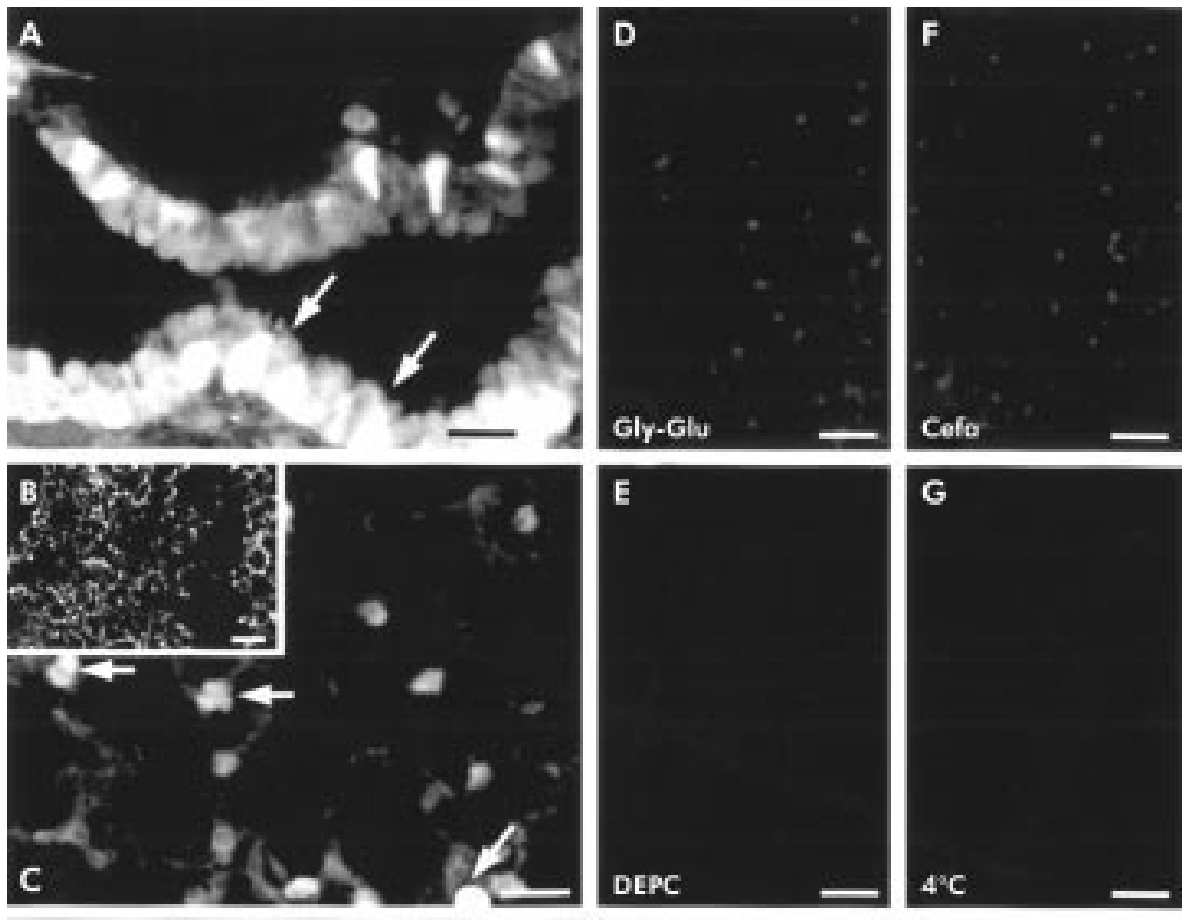

Uptoke

Intibition

Figure 4 Ex vivo uptake studies in cystic fibrosis lungs. Uptake studies with peripheral cystic fibrosis lung tissues with the reporter molecule D-Ala--Lys-AMCA led to uptake and intracellular fluorescence in (A) bronchial cells and (B, C) type II pneumocytes. Inhibition studies with $1 \mathrm{mM}$ of the competitive glycyl---glutamine (D) or cefadroxil (F) to the same concentration of D-Ala--Lys-AMCA did not result in accumulation of fluorescence. Incubations in the presence of the inhibitor DEPC (E) and at $4^{\circ} \mathrm{C}$ to exclude non-specific uptake $(\mathrm{G})$ also did not lead to fluorescence signalling. Bar $=42 \mu \mathrm{m}(A, C-G), 300 \mu \mathrm{m}(B)$. 
Table 2 Summary of cellular uptake activity in peripheral lung

\begin{tabular}{lll}
\hline Tissue structure & Normal & Cystic fibrosis \\
\hline Epithelial cells & & \\
Bronchiolar & +++ & +++ \\
Alveolar type I & 0 & 0 \\
Alveolar type II & +++ & +++ \\
Macrophages & 0 & 0 \\
Capillaries & 0 & 0
\end{tabular}

Scoring of intensitiy of staining from 0 to +++

\section{DISCUSSION}

In chronic and acute lung infections the alveolar and bronchial epithelium is a site with major significance for drug delivery and treatment. The surface area of the human lung (approximately $140 \mathrm{~m}^{2}$ ) provides a unique site for drug absorption. In developing new strategies for aerosol delivery of drug treatment with peptidomimetics it is necessary to identify the cellular sites and functional properties of drug transporters that can be targeted. The present study demonstrates the presence, localisation, and functionality of the high affinity type peptide transporter PEPT2 in bronchial epithelium and type II pneumocytes of normal and CF human airways.

Earlier studies using RT-PCR and northern blotting have reported the expression of PEPT2 but not PEPT1 mRNA in lung tissues. ${ }^{8}{ }^{15} 33$ Immunohistochemical studies were carried out to determine the exact cellular site of the transporter. Our results show the expression of PEPT2 immunoreactivity in type II pneumocytes, which confirms the findings of recent uptake experiments that reported dipeptide ${ }^{34}$ and tripeptide ${ }^{35}$ transport in rat type II cells. Furthermore, by localising PEPT2 to the bronchial epithelium we have identified a new route of transport for peptidomimetics in larger airways that has been previously predicted. ${ }^{36}$

Since all previous functional studies on the transport of oligopeptides have only been carried out on cell cultures or animal preparations which do not necessarily reflect the human conditions in vivo, we designed ex vivo uptake experiments on human peripheral lung tissues to study functional peptide transport in human cells located in a complex tissue. The dipeptide derivative D-Ala-L-Lys-AMCA was chosen as reporter molecule because of its capability for specific transport via PEPT2 and PEPT1. ${ }^{29} 3033$ Uptake of D-Ala-L-Lys-AMCA into type II cells and bronchial epithelium confirmed the morphological data obtained by immunohistochemical analysis.

Two strategies were employed to exclude non-specific fragmental uptake of D-Ala-L-Lys-AMCA fragments: (1) incorporation of the $\mathrm{NH}_{2}$ terminal D-Ala residue was chosen to render the compound resistant to peptidases, and (2) the medium MEM-21011 containing high concentrations of free amino acids which would act as competitive inhibitors for fragments of D-Ala-L-Lys-AMCA was used to exclude uptake via amino acid transporters.

As shown by fluorescence accumulation studies, uptake was competitively inhibited by cefadroxil and glycyl-L-glutamine which are both PEPT2 substrates. Since captopril, which is only transported by PEPT1 and not by PEPT2, did not compete with the reporter molecule, it was concluded that the transport of D-Ala-L-Lys-AMCA was specific for PEPT2. This was validated by the immunohistochemical results. Besides the competitive inhibition of D-Ala-L-Lys-AMCA uptake by oligopeptide transporter substrates, blocking peptide transport with diethylpyrocarbonate, which has previously been shown to act as an inhibitor ${ }^{31}{ }^{32}$ by modification of important His residues, provides further evidence for the specificity of the transport process. Any non-carrier mediated passive diffusion was excluded by the lack of transport into cellular structures other than those that also show immunoreactivity for PEPT2, and by incubation at $4^{\circ} \mathrm{C}$ when no fluorescence accumulation was observed.

In patients suffering from CF recurrent bacterial infections play a critical part in progression of the disease. There have been numerous studies of ways to optimise administration of antibiotics and aerosol delivery is thought to be an attractive approach for the treatment of many respiratory infections, ${ }^{5637}$ although the efficacy of aerosol therapy is affected by a number of variables and is still controversial. However, clinical trials have shown certain benefits when antibiotics are administered by inhalation. ${ }^{7}$ The inhibition of D-Ala-L-Lys-AMCA by cefadroxil in normal and CF human lung tissue reported in this study provides the first data on the cellular transport pathways of distinct antibiotics.

However, expression of the transporter PEPT2 may not enhance the activity of topical antibiotics as it may take them away from the site of infection. In this respect, the epithelial lining fluid and macrophages have been regarded as the preferred site for antibiotic deposition. ${ }^{38}$ By intracellular uptake into epithelial cells, PEPT2 may reduce the concentration of antibiotic in the lining fluid.

Cefadroxil is a semi-synthetic cephalosporin which has been proved to be effective in pulmonary infections caused by Gram negative and Gram positive pathogens. ${ }^{39}$ As has been shown previously, it is a very effective substrate for transport by PEPT2 in renal brush border membrane vesicles.$^{40}$ In addition to its use as an antibiotic, it is also effective in reducing antigen induced bronchial hyperresponsiveness. ${ }^{41}$ This effect is not linked to the reduction in accumulation of eosinophils.

Immunohistochemical studies and ex vivo uptake experiments were performed in patients with CF to determine whether transporter expression and functionality is impaired in the lungs of these patients. No significant alteration in the distribution pattern of PEPT2 immunoreactivity was seen. Although a similar cellular distribution of the transporter protein expression was seen, the higher amount of mucus retention in the CF specimens markedly reduced the tissue penetration of the reporter molecule during the uptake studies and therefore decreased its tissue accumulation quantitatively. However, because of the small number of CF tissues studied and limited sensitivity, the results should not be extrapolated to all stages of CF lung disease. In this respect, the present study was primarily designed to establish a preliminary visualising uptake assay with human tissues. This assay, which can also be used with other organs, could be used to identify new peptidomimetic substrates of the transporters PEPT2 and PEPTI.

These data reflect an interesting finding that relates lung peptide transport to photodynamic therapy (PDT). ${ }^{42}$ There are only a few reports on the uptake mechanisms of photosensitisers in mammalian tissues. ${ }^{43}$ We have previously reported the carrier mediated transport of $\delta$-ALA by both mammalian peptide transport systems. ${ }^{22}$ Together with this report, the expression profile of PEPT2 shown in this study provides a basis for a clearer understanding of the mechanisms of pulmonary uptake of $\delta$-ALA in human airway tissue.

In conclusion, we have examined the expression of the peptide transporter PEPT2 in normal and CF human lungs and found PEPT2 immunoreactivity in different areas of the respiratory tract. Moreover, ex vivo uptake experiments demonstrated a pattern of transport activity that was structurally identical in CF and normal tissues. Mucus retention in the CF specimens, however, reduced the uptake of the reporter molecule quantitatively. Together with recent information on the minimal molecular requirements of substrates for recognition by peptide transporters, ${ }^{44}$ our findings provide new insights into pulmonary transport pathways and peptide metabolism and the perspectives of optimising drug treatment by targeting a potent membrane transport protein. 


\section{ACKNOWLEDGEMENTS}

The authors thank J Springer and C Peiser for their useful comments, and R Strozynski, S Wiegand, P Hartmann, M Bodenbenner and T Jura for their skilful technical assistance. Support from the German Academic Exchange Service (DAAD, D/00/10559) and the EU (Biomed II) is gratefully acknowledged.

\section{Authors' affiliations}

D A Groneberg, Q Thai Dinh, A Fischer, Department of Pediatric Pneumology and Immunology, Charité Campus Virchow, Humboldt University, Augustenburger Platz 1, D-13353 Berlin, Germany D A Groneberg, P R Eynott, T Oates, P J Barnes, K F Chung, Department of Thoracic Medicine, National Heart \& Lung Institute, Imperial College of Science, Technology and Medicine, London SW3 6LY, UK

F Döring, H Daniel, Institute of Nutritional Sciences, Technical University of Munich, Hochfeldweg 2, D-85350 Freising, Germany

\section{REFERENCES}

1 Koch C, Hoiby N. Pathogenesis of cystic fibrosis. Lancet 1993;341:1065-9

2 Rosenstein BJ, Zeitlin PL. Prognosis in cystic fibrosis. Curr Opin Pulm Med 1995:1:444-9.

3 Ramsey BW. Management of pulmonary disease in patients with cystic fibrosis. N Engl J Med 1996;335:179-88.

4 Honeybourne D. Antibiotic penetration into lung tissues (editorial). Thorax 1994;49: 104-6.

5 Hodson ME, Penketh AR, Batten JC. Aerosol carbenicillin and gentamicin treatment of Pseudomonas aeruginosa infection in patients with cystic fibrosis. Lancet $1981 ;$ ii: 1137-9.

6 Bressolle F, de la Coussaye JE, Ayoub R, et al. Endotracheal and aerosol administrations of ceftazidime in patients with nosocomia pneumonia: pharmacokinetics and absolute bioavailability. Antimicrob Agents Chemother 1992;36:1404-11

7 Nolan G, Moivor P, Levison H, et al. Antibiotic prophylaxis in cystic fibrosis: inhaled cephaloridine as an adjunct to oral cloxacillin. J Pediatr 1982;101:626-30.

8 Boll $M$, Herget $M$, Wagener $M$, et al. Expression cloning and functional characterization of the kidney cortex high-affinity proton-coupled peptide transporter. Proc Natl Acad Sci USA 1996;93:284-9.

9 Saito H, Terada T, Okuda M, et al. Molecular cloning and tissue distribution of rat peptide transporter PEPT2. Biochim Biophys Acta 1996:1280:173-7.

10 Liu W, Liang R, Ramamoorthy S, et al. Molecular cloning of PEPT 2, a new member of the $\mathrm{H}^{+}$/peptide cotransporter family, from human kidney. Biochim Biophys Acta 1995;1235:461-6.

11 Wang H, Fei YJ, Ganapathy V, et al. Electrophysiological characteristics of the proton-coupled peptide transporter PEPT2 cloned from rat brain. Am J Physiol 1998;275:C967-75.

12 Boll M, Markovich D, Weber WM, et al. Expression cloning of a cDNA from rabbit small intestine related to proton-coupled transport of peptides, beta-lactam antibiotics and ACE-inhibitors. Pflugers Arch 1994:429: 146-9.

13 Fei YJ, Kanai Y, Nussberger S, et al. Expression cloning of a mammalian proton-coupled oligopeptide transporter. Nature 1994;368:563-6.

14 Liang R, Fei YJ, Prasad PD, et al. Human intestinal $\mathrm{H}^{+} /$peptide cotransporter. Cloning, functional expression, and chromosomal localization. J Biol Chem 1995;270:6456-63.

15 Saito $\mathbf{H}$, Okuda M, Terada T, et al. Cloning and characterization of a rat $\mathrm{H}^{+}$/peptide cotransporter mediating absorption of beta-lactam antibiotics in the intestine and kidney. J Pharmacol Exp Ther 1995;275:1631-7.

16 Daniel H, Herget $M$. Cellular and molecular mechanisms of renal peptide transport. Am J Physiol 1997;273:F1-8.

17 Freeman TC, Bentsen BS, Thwaites DT, et al. $\mathrm{H}^{+} /$di-tripeptide transporter (PepT1) expression in the rabbit intestine. Pflugers Arch 1995:430:394-400

18 Ogihara $\mathrm{H}$, Saito $\mathrm{H}$, Shin $\mathrm{BC}$, et al. Immuno-localization of $\mathrm{H}^{+} /$peptide cotransporter in rat digestive tract. Biochem Biophys Res Commun 1996;220:848-52
19 Ogihara H, Suzuki T, Nagamachi Y, et al. Peptide transporter in the rat small intestine: ultrastructural localization and the effect of starvation and administration of amino acids. Histochem J 1999;31:169-74.

20 Smith DE, Pavlova A, Berger UV, et al. Tubular localization and tissue distribution of peptide transporters in rat kidney. Pharm Res 1998; 15:1244-9.

21 Shen $\mathbf{H}$, Smith DE, Yang T, et al. Localization of PEPT1 and PEPT2 proton-coupled oligopeptide transporter mRNA and protein in rat kidney. Am J Physiol 1999;276:F658-65.

22 Doring $\mathbf{F}$, Walter J, Will J, et al. Delta-aminolevulinic acid transport by intestinal and renal peptide transporters and its physiological and clinical implications. J Clin Invest 1998;101:2761-7.

23 Berger UV, Hediger MA. Distribution of peptide transporter PEPT2 mRNA in the rat nervous system. Anat Embryol (Berl) 1999;199:439-49.

24 Groneberg DA, Doring F, Nickolaus M, et al. Expression of PEPT2 peptide transporter mRNA and protein in glial cells of rat dorsal roo ganglia. Neurosci Lett 2001;304:181-4.

25 Daniel H. Function and molecular structure of brush border membrane peptide/ $\mathrm{H}^{+}$symporters. J Membr Biol 1996;154:197-203.

26 Doring F, Michel T, Rosel A, et al. Expression of the mammalian renal peptide transporter PEPT2 in the yeast Pichia pastoris and applications of the yeast system for functional analysis. Mol Membr Biol 1998;15:79-88.

27 Otto C, Dieck ST, Baver K. Dipeptide uptake by adenohypophysial folliculostellate cells. Am J Physiol 1996;271:C210-7.

28 Otto C, Baver K. Dipeptide uptake: a novel marker for testicular and ovarian macrophages. Anat Rec 1996;245:662-7.

29 Wenzel U, Diehl D, Herget $M$, et al. Regulation of the high-affinity $\mathrm{H}^{+}$/peptide cotransporter in renal LLC-PK1 cells. J Cell Physiol 1999; 178:341-8.

30 Dieck ST, Hever H, Ehrchen J, et al. The peptide transporter PepT2 is expressed in rat brain and mediates the accumulation of the fluorescent dipeptide derivative beta-Ala-Lys-Nepsilon-AMCA in astrocytes. Glia 1999;25:10-20.

31 Kramer W, Girbig F, Petzoldt E, et al. Inactivation of the intestinal uptake system for beta-lactam antibiotics by diethylpyrocarbonate. Biochim Biophys Acta 1988;943:288-96.

32 Terada T, Saito H, Invi K. Interaction of beta-lactam antibiotics with histidine residue of rat $\mathrm{H}^{+}$/peptide cotransporters, PEPT1 and PEPT2. Biol Chem 1998:273:5582-5.

33 Groneberg DA, Nickolaus M, Springer J, et al. Localization of the peptide transporter PEPT2 in the lung: implications for pulmonary oligopeptide uptake. Am J Pathol 2001;158:707-14.

34 Meredith D, Boyd CA. Dipeptide transport characteristics of the apical membrane of rat lung type II pneumocytes. Am J Physiol 1995:269:L137-43

35 Helliwell PA, Meredith D, Boyd CA, et al. Tripeptide transport in rat lung. Biochim Biophys Acta 1994;1190:430-4.

36 Yamashita F, Kim KJ, Lee VH. Dipeptide uptake and transport characteristics in rabbit tracheal epithelial cell layers cultured at an ai interface. Pharm Res 1998;15:979-83.

37 Sustronck B, Deprez P, Muylle E, et al. Evaluation of the nebulisation of sodium ceftiofur in the treatment of experimental Pasteurella haemolytica bronchopneumonia in calves. Res Vet Sci 1995;59:267-71.

38 Retsema JA, Girard AE, Girard D, et al. Relationship of high tissue concentrations of azithromycin to bactericidal activity and efficacy in vivo. J Antimicrob Chemother 1990;25:83-9.

39 Chisholm DR, DeRegis RG, Behr DA. Therapeutic efficacy of cefadroxil and cephalexin for pneumonia in a rat test model. Antimicrob Agents Chemother 1986;30:105-9.

40 Ries M, Wenzel U, Daniel H. Transport of cefadroxil in rat kidney brush-border membranes is mediated by two electrogenic $\mathrm{H}^{+}$-coupled systems. J Pharmacol Exp Ther 1994:271:1327-33.

41 Boichot $E$, Richard MP, Paubert-Braquet M. Effect of cefadroxil on antigen-induced bronchial hyperresponsiveness and eosinophil accumulation in lung from sensitized guinea pigs. Int Arch Allergy Immunol 1993;102:87-93.

42 Rowe PM. Photodynamic therapy begins to shine. Lancet 1998;351:1496.

43 Peng Q, Moan J, Ma LW, et al. Uptake, localization, and photodynamic effect of meso-tetra(hydroxyphenyl)porphine and its corresponding chlorine in normal and tumor tissues of mice bearing mammary carcinoma. Cancer Res 1995;55:2620-6.

44 Doring F, Will J, Amasheh S, et al. Minimal molecular determinants of substrates for recognition by the intestinal peptide transporter. J Biol Chem 1998;273:23211-8. 